\title{
THE DIFFUSION OF FERRO- AND FERRICYANIDE IONS IN AQUEOUS SOLUTIONS OF SODIUM HYDROXIDE*
}

\author{
J. C. BazÁn and A. J. ARvia \\ Instituto Superior de Investigaciones, Facultad de Química y Farmacia, \\ Universidad Nacional de La Plata, La Plata, Argentina
}

\begin{abstract}
The diffusion of ferri- and ferrocyanide ions in sodium hydroxide solutions has been studied by means of a platinum rotating disk electrode. Results were obtained at variable concentrations and in the range of temperature between 24 and $40^{\circ} \mathrm{C}$.

The product $D \eta / T$ was approximately constant and independent of temperature in the range studied. The dependence of $D$ on the total ionic strength is mainly due to the change of viscosity at large ionic concentration.

Résumé-On a étudié la diffusion des ions ferri- et du ferrocyanure dans des solutions d'hydroxyde de sodium au moyen d'une électrode à disque tournant en platine. On a effectué les mesures à différentes concentrations et à des température comprises entre 24 et $40^{\circ} \mathrm{C}$.

Dans le domaine étudié, l'expression $D \eta / T$ était pratiquement constante et indépendente de la température. La variation de $D$ avec la force ionique totale est due principalment au changement de la viscosité causé par la grande concentration ionique.

Zusammenfassung -Der Diffusionskoeffizient von Ferri- und Ferrocyanid ions in Natriumhydroxydlosungen wurde mittels einer rotierenden Scheibenelektrode aus Platin untersucht. Die Messungen wurden bei verschiedene Konzentrationen und bei Temperaturen zwischen 24 und $40^{\circ} \mathrm{C}$ ausgeführt.

Das Produkt $D \eta / T$ war ungefahr konstant und im untersuchten Gebiet von der Temperatur unabhängig. Die Abhängigkeit von $D$ von der gesamten Ionenstärke ist hauptsächlich auf die Ãnderung der Zahigkeit infolge der hohen Konzentration zurückzuführen.
\end{abstract}

\section{INTRODUCTION}

FOR studying the mass transfer rate in electrochemical systems solutions containing potassium ferro- and ferricyanide and sodium hydroxide in excess have very often been used, because the redox reaction involved can be studied in both directions on activated nickel or platinum electrodes and the limiting current density related to the reaction under convective-diffusion control is casily determined.

As data reported in the literature ${ }^{\mathbf{1 . 2}}$ about the diffusion coefficients of potassium ferro- and ferricyanide are for ternary solutions where the concentration of the supporting electrolyte was not appreciably changed, we decided to evaluate them within a larger range of concentration, employing a different experimental technique. Electrochemical determination by means of the rotating disk electrode ${ }^{3}$ was chosen. The rotating disk electrode has been successfully tested for this type of measurement by different authors especially Yuktanova. ${ }^{4}$ Results were satisfactorily compared to the very accurate determinations of von Stackelberg. ${ }^{5}$ The rotating disk electrode offers the advantage of determining diffusion coefficients in a reasonably short time.

In the present work the effect of the concentration of the various species in the solution and of the temperature on the diffusion coefficient was determined.

\section{EXPERIMENTAL TECHNIQUE}

Electrolysis cell and rotating disk electrode. A double wall Pyrex vessel was used as the electrolysis cell. It had a Lucite cover holding the reference and the counterelectrode. The rotating disk electrode was placed axially in the middle of the container.

- Manuscript received 20 July 1964; as amended, 22, December 1964. 
A circular platinum sheet was placed symmetrically at the bottom of the container. A platinum electrode arranged in a separate compartment, filled with the solution and ending in a capillary tip was used as a reference electrode.

The cell design allowed the possibility of maintaining an inert atmosphere and the bubbling of purified nitrogen prior to electrolysis.

The working electrode was a platinum disk of $0.31 \mathrm{~cm}$ in diameter embedded in a Lucite rod of $1 \mathrm{~cm}$ diameter and welded to it with a small amount of an inert resin. The piece was adjusted and centred on the end of the rotating shaft. Its apparent area was $0.0754 \mathrm{~cm}^{2}$.

The electrode was driven by an ac $1 / 8 \mathrm{hp}$ motor electronically regulated. The rotation rate could be set between 20 and $1500 \mathrm{rpm}$ with a maximum relative error, at the lower rates, of $1 \%$. It was measured with a Zeiss stroboscope and regularly checked.

\section{Procedure}

Aqueous solutions of potassium ferro- and ferricyanide were used; the ratio between the salts ranged from 0.08 to 10 . The supporting electrolyte was sodium hydroxide; its concentration ranged from 0.5 to $2.0 \mathrm{M}$. The ratio between concentration of supporting electrolyte and diffusing ions was kept at about 20 or larger. The concentration of each component of the solution was determined by chemical analysis. The viscosity and density of solutions were determined as usual.

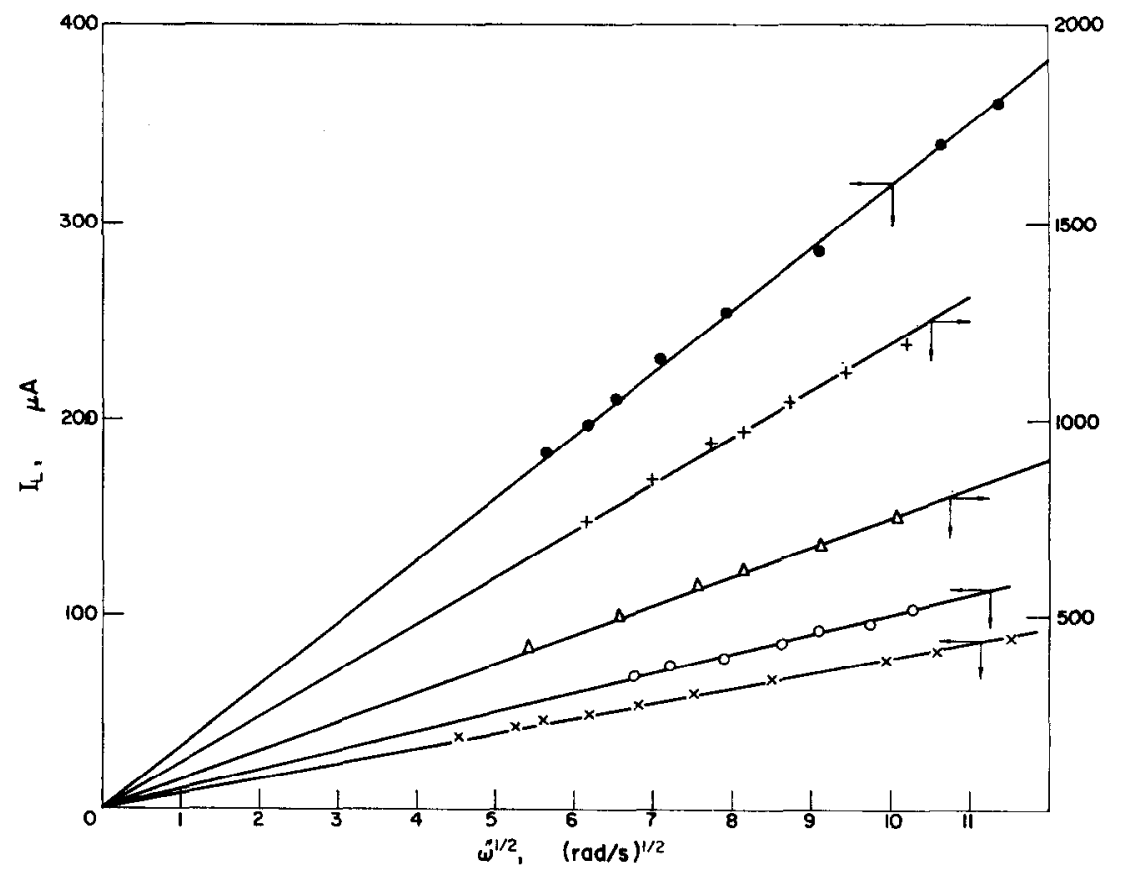

FIG. 1. $I_{L} v s \omega^{1 / 2}$. Oxidation of ferrocyanide ion. $25^{\circ} \mathrm{C}$.

- $\mathrm{C}_{\mathrm{h}}: 1.014, \mathrm{C}_{3} \times 10^{2}: 1.00, \mathrm{C}_{4} \times 10^{2}: 1.04$

$+C_{h}: 2 \cdot 070, C_{3} \times 10^{2}: 9.80, C_{4} \times 10^{2}: 2 \cdot 44$

$\Delta C_{h}: 1.084, C_{3} \times 10^{2}: 2.50, C_{4} \times 10^{2}: 2.38$

$C_{h}: 0.5170, C_{8} \times 10^{2}: 0.32, C_{4} \times 10^{2}: 0.31$

$\times C_{h}: 1.031, C_{3} \times 10^{2}: 0.25, C_{4} \times 10^{2}: 0.27$ 


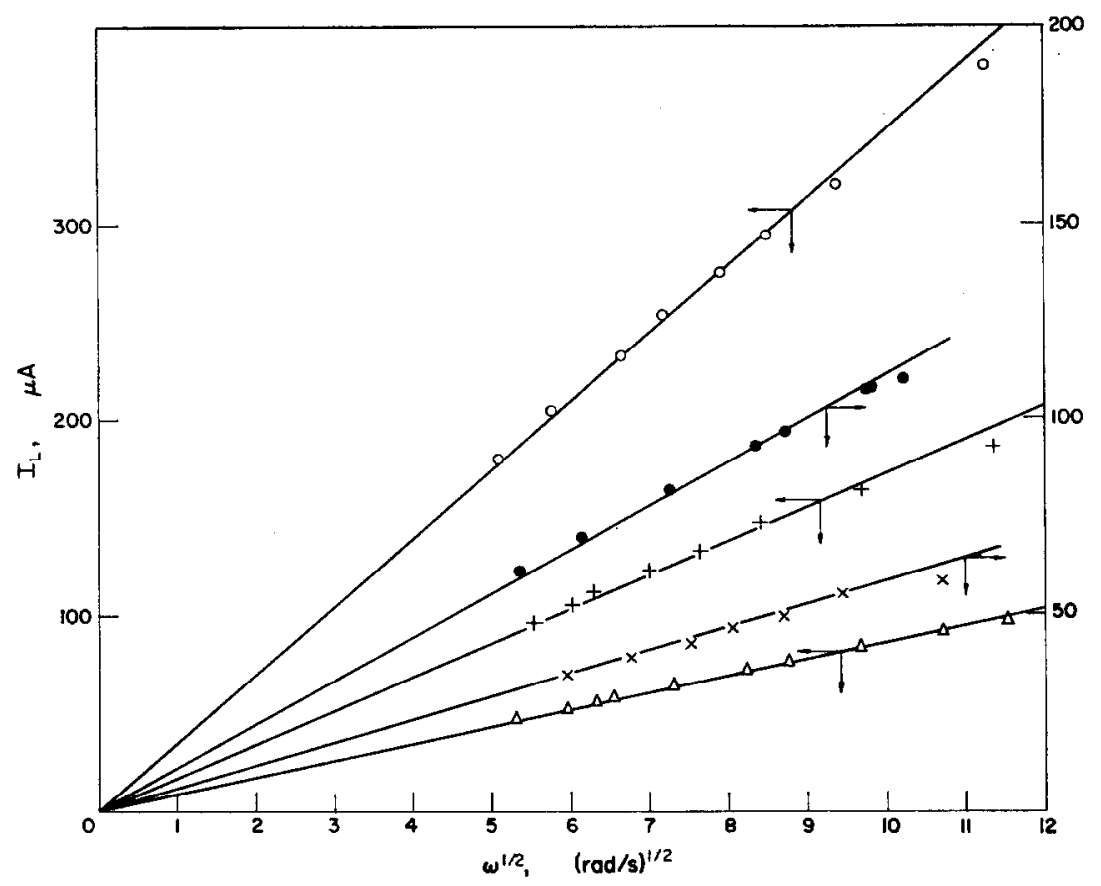

FIG. 2. $I_{L}$ vs $\omega^{1 / 2}$. Reduction of ferricyanide ion. $25^{\circ} \mathrm{C}$.

$O \mathrm{Ch}_{\mathrm{h}}: 1.014, \mathrm{C}_{\mathrm{8}} \times 10^{2}: 1.00, \mathrm{C}_{\mathrm{a}} \times 10^{2}: 1.04$

- $C_{h}: 0.5170, C_{8} \times 10^{2}: 0.32, C_{4} \times 10^{2}: 0.31$

$+C_{h}: 1.031, C_{3} \times 10^{2}: 0.50, C_{4} \times 10^{2}: 0.53$

$\times C_{\mathrm{h}}: 0.5195, \mathrm{C}_{3} \times 10^{2}: 0.16, \mathrm{C}_{4} \times 10^{2}: 0.16$

$\triangle C_{h}: 1 \cdot 031, C_{3} \times 10^{2}: 0.25, C_{4} \times 10^{2}: 0.27$

Experiments were performed at temperatures between 24 and $40^{\circ} \mathrm{C}$. Solutions were prepared with analytical reagent chemicals, EKA and MERCK.

According to circumstances the working electrode was the anode or cathode of the cell. The limiting current flowing through the cell was measured as usual by means of conventional circuitry. ${ }^{6}$ Current voltage curves for a chosen set of experimental conditions were determined at different rotation rates, from 300 to $1500 \mathrm{rpm}$. These curves show the usual behaviour of reversible reactions comprising two soluble species entering the electrochemical reaction.

\section{Diffusion coefficients}

\section{RESULTS}

To calculate the experimental diffusion coefficients the equation deduced by Levich ${ }^{3}$ for limiting current density under convective-diffusion control for the rotating disk electrode was used,

$$
i_{L}=\frac{z F}{1 \cdot 61} c_{i} D_{i}{ }^{2 / 3} v^{-1 / 6} \omega^{1 / 2},
$$

where $i_{L}$ is the limiting current density in $\mathrm{A} / \mathrm{cm}^{2}, c_{i}$ the concentration of the diffusing species in mole $/ \mathrm{cm}^{3}, D$ its diffusion coefficient in $\mathrm{cm}^{2} / \mathrm{s}, \nu$ the kinematic viscosity of the solution in $\mathrm{cm}^{2} / \mathrm{s}$ and $\omega$ the rotation rate of the electrode in rads/s.

The determination of the dependence of $i_{L}$ on $\omega$ thus allows the calculation of $D$. In Fig. 1 and 2 some results obtained from the anodic and cathodic experiments are 
TABLE 1

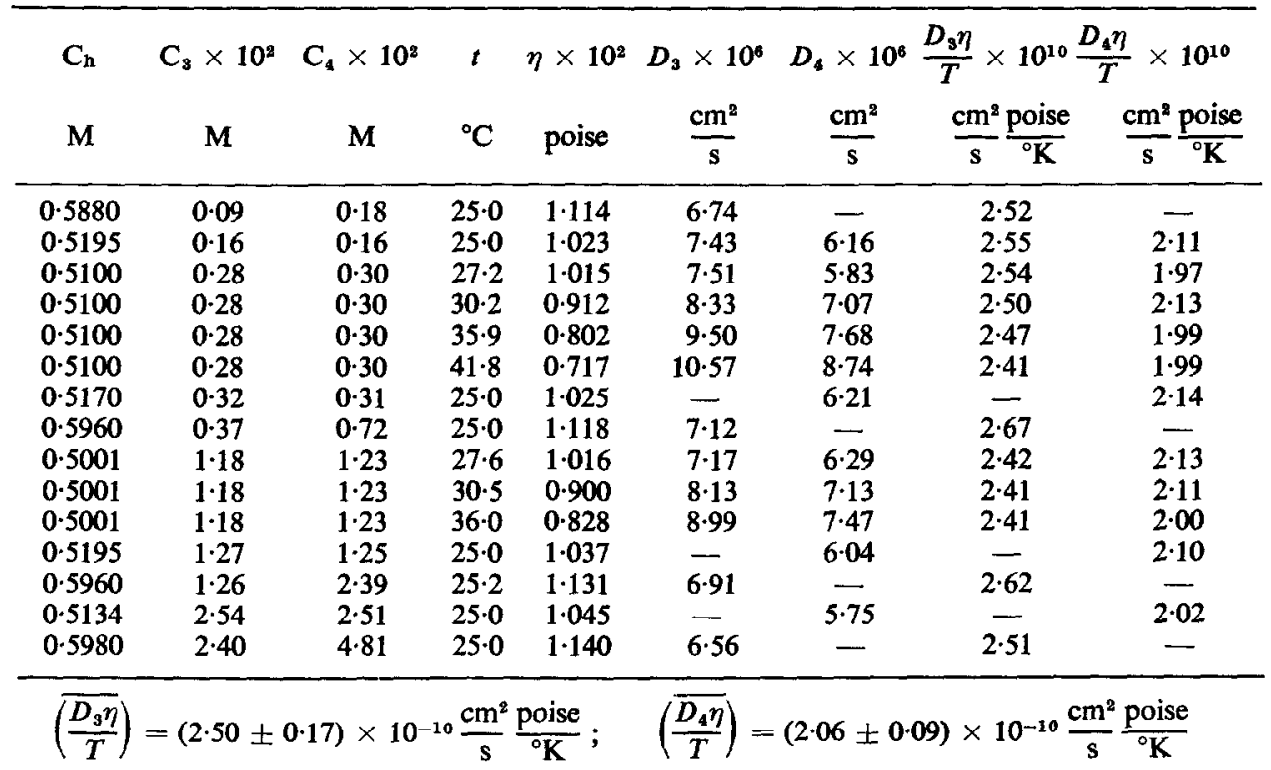

shown. The slope of the best straight lines obtained from a plot of $i_{L} v s \omega^{1 / 2}$ were used in the calculations and the results are assembled in Tables 1,2 and 3. In the same tables dynamic viscosity, $\eta$, in $\mathrm{g} / \mathrm{cm} . \mathrm{s}$ and also the quotient $D \eta / T$, where $T$ is the temperature in ${ }^{\circ} \mathrm{K}$, were added. $\mathrm{C}_{3}, \mathrm{C}_{4}$ and $\mathrm{C}_{\mathrm{h}}$ are the molar concentrations of potassium ferricyanide, potassium ferrocyanide and sodium hydroxide, respectively.

\section{Effect of temperature}

The experimental diffusion coefficients fit an exponential law with respect to temperature, as shown in Fig. 3. The average experimental energy of activation from the Arrhenius plot is $4100 \pm 250 \mathrm{cal} / \mathrm{mole}$.

A similar law was followed by the dependence of viscosity on temperature, as

TABLE 2

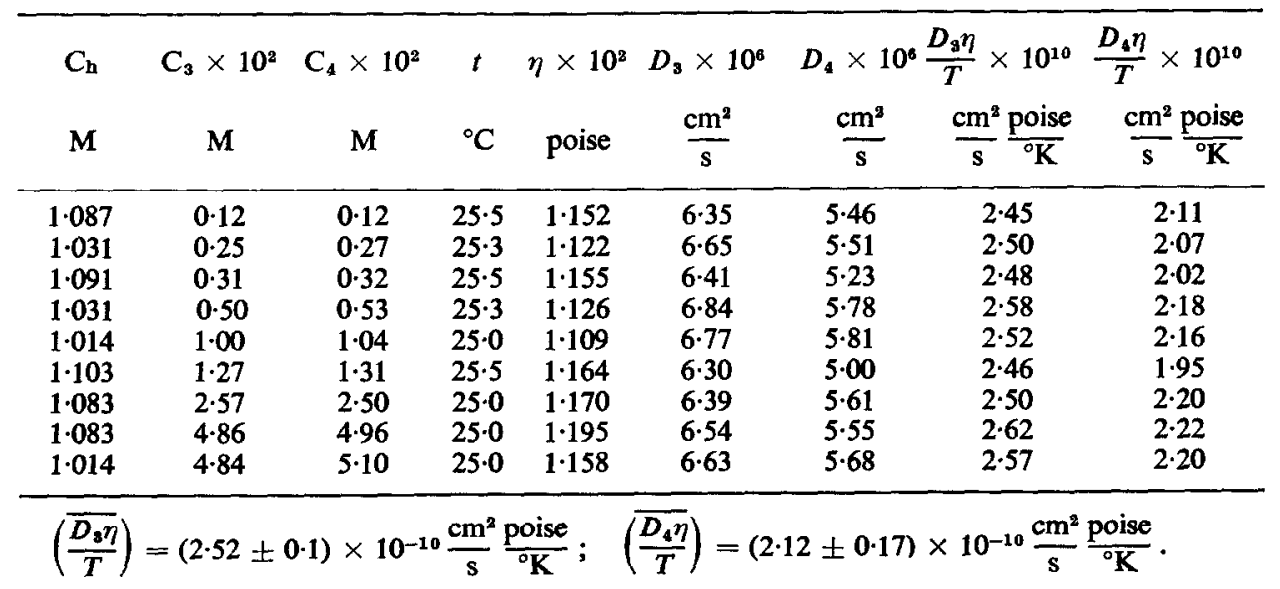


TABLE 3.

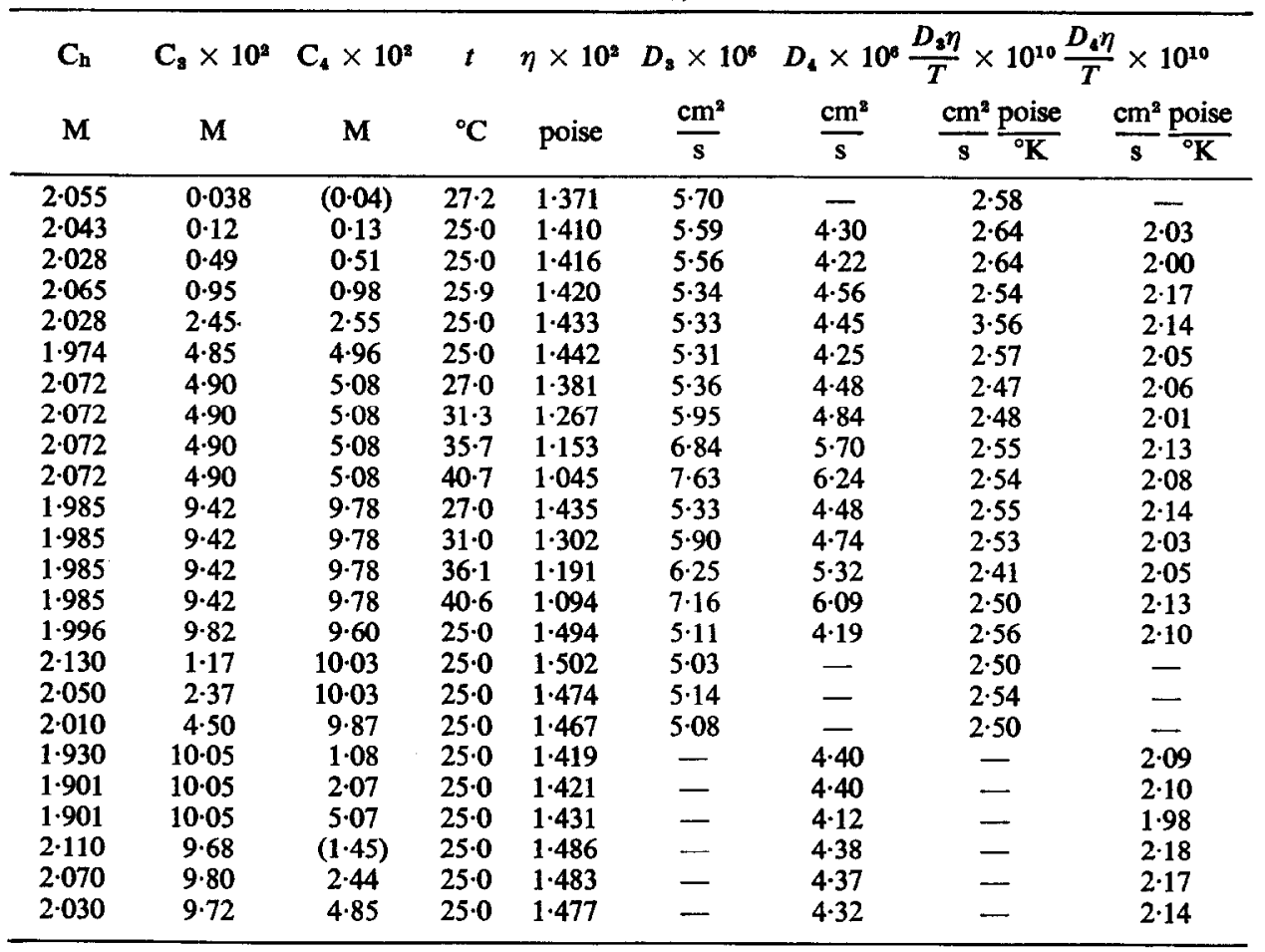

$\left(\overline{\frac{D_{s} \eta}{T}}\right)=(2.54 \pm 0.13) \times 10^{-10} \frac{\mathrm{cm}^{2}}{\mathrm{~s}} \frac{\text { poise }}{{ }^{\circ} \mathrm{K}} ; \quad\left(\overline{\frac{D_{4} \eta}{T}}\right)=(2.09 \pm 0.11) \times 10^{-10} \frac{\mathrm{cm}^{2}}{\mathrm{~s}} \frac{\text { poise }}{{ }^{\circ} \mathrm{K}}$.

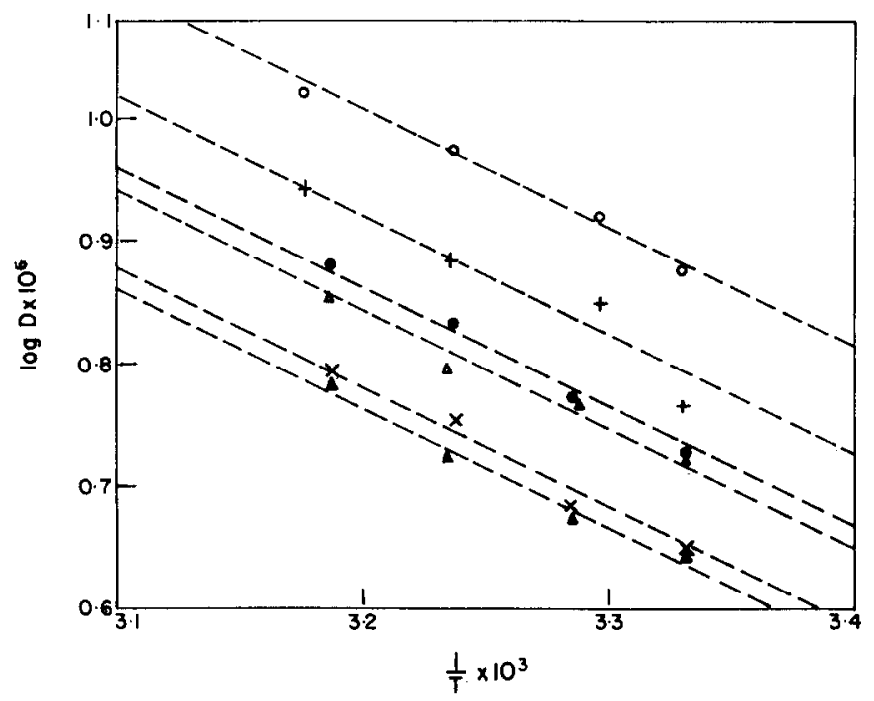

FIG. 3. Arrhenius plot for the diffusion coefficients. Dotted straight lines were drawn with the average value of the experimental energy of activation for diffusion.

$C_{h}: 0.5100, C_{2} \times 10^{2}: 0.28, C_{4} \times 10^{2}: 0.30\left(D_{2}: O, D_{4}:+\right)$

$C_{h}: 2.072, C_{3} \times 10^{2}: 4.90, C_{4} \times 10^{2}: 5.08\left(D_{2}: 0, D_{4}: \times\right)$

$C_{h}: 1.985, C_{3} \times 10^{2}: 9 \cdot 42, C_{4} \times 10^{2}: 9.78\left(D_{3}: \Delta, D_{4}: \Delta\right)$ 
indicated in Fig. 4, and as can be predicted, the thermal effect is opposed to that found for the diffusion coefficient. The experimental energy of activation in this case equals $3900 \pm 100 \mathrm{cal} / \mathrm{mol}$.

\section{Concentration dependence}

The concentration of the diffusing entities was changed in order to make the migration term negligible compared to the convective diffusion term in the ionic mass-

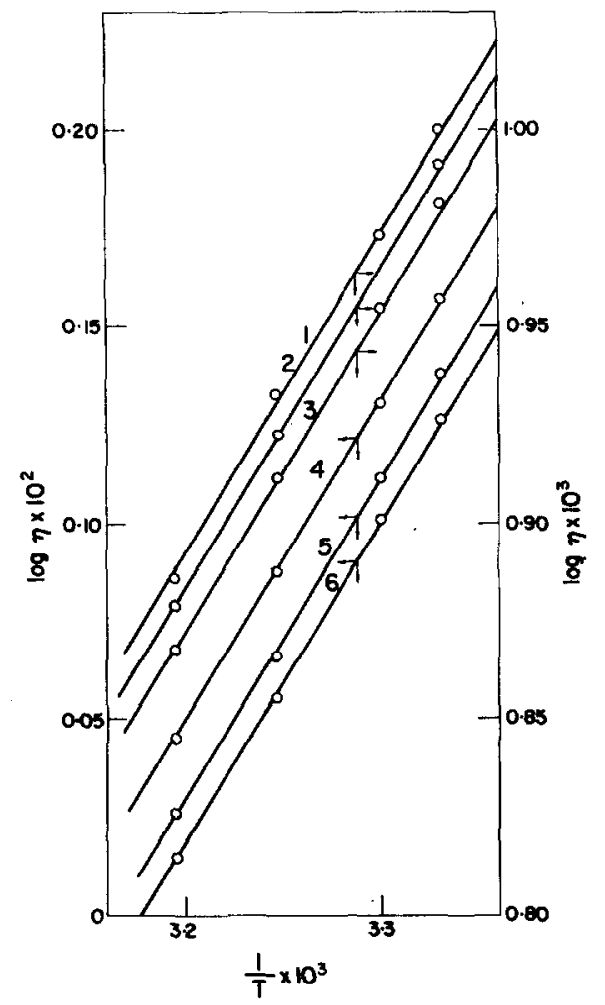

FIG. 4. Arrhenius plot for dynamic viscosity.

(1) $\mathrm{C}_{\mathrm{h}}: 0.5001, \mathrm{C}_{3} \times 10^{2}: 2.37, \mathrm{C}_{4} \times 10^{2}: 2.37$

(2) $C_{h}: 0.5001, C_{s} \times 10^{2}: 1 \cdot 18, C_{4} \times 10^{2}: 1.23$

(3) $\mathrm{C}_{\mathrm{h}}: 0.5100, \mathrm{C}_{\mathrm{s}} \times 10^{2}: 0.28, \mathrm{C}_{4} \times 10^{2}: 0.30$

(4) $\mathrm{C}_{\mathrm{b}}: 1.985, \mathrm{C}_{8} \times 10^{2}: 9.42, \mathrm{C}_{4} \times 10^{2}: 9.78$

(5) $C_{h}: 2.072, C_{s} \times 10^{2}: 4.90, C_{4} \times 10^{2}: 5.08$

(6) $\mathrm{C}_{\mathrm{h}}: 2.065, \mathrm{C}_{3} \times 10^{2}: 0.95, \mathrm{C}_{4} \times 10^{2}: 0.98$

transfer equation. The experimental diffusion coefficient shows a slight dependence on the concentration of the diffusing species, tending to a very slow decrease when concentration is increased.

The extrapolated diffusion coefficients at zero concentration of the diffusing entities are plotted in Fig. 5 against the concentration of the supporting electrolyte. The diffusion coefficient shown at zero ionic strength for both ferro- and ferri-cyanide ions were obtained from molar ionic conductivity according to the Nernst-Hartley equation. ${ }^{7.8}$ It is clear that the diffusion coefficient increases as the total ionic strength decreases. 


\section{Accuracy of results}

Considering the weight of each term in equation (1), the maximum experimental error affecting the calculated diffusion coefficient amounts from 3 per cent for the solutions of higher concentration up to 10 per cent for the more diluted ones.

\section{DISCUSSION}

It is evident that the electrolytic system studied in the present case is complex. Although our first purpose was to extend knowledge of experimental diffusion coefficients of ferro- and ferricyanide ions in sodiumhy droxide solutions, a brief discussion of the foregoing results may be of interest.

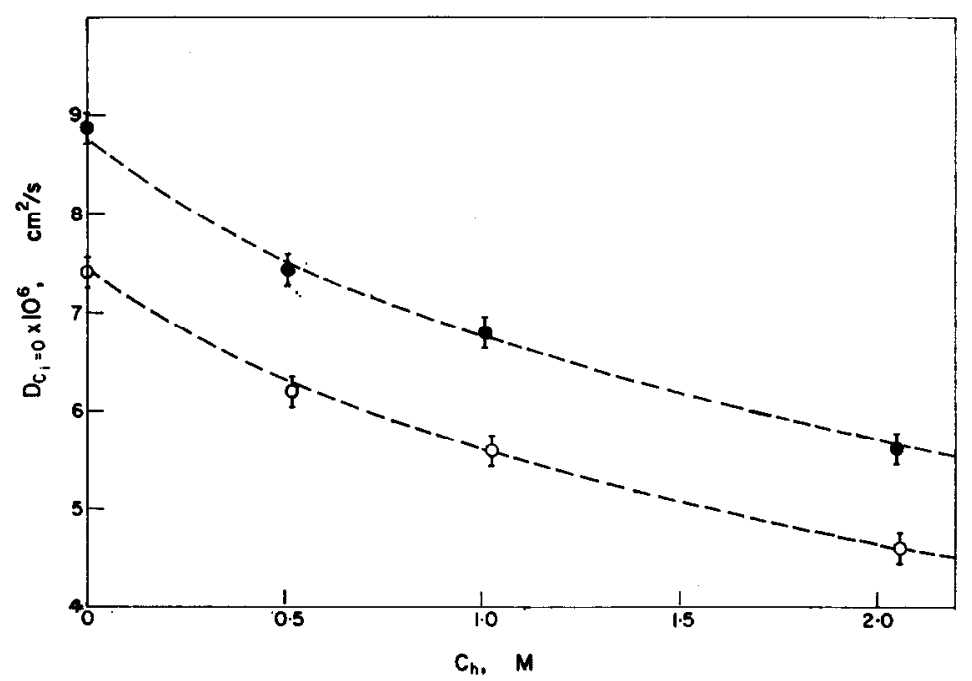

Fig. 5. Diffusion coefficients at zero concentration versus concentration of the supporting electrolyte. $D_{3}: \odot$ and $D_{4}: 0$.

One feature to emphasize is the relatively small effect of the concentration of the diffusing species on the experimental diffusion coefficient within the range of concentration of this work. A second is the net effect of the total ionic strength. The facts agree with the general predictions of the theory of diffusion coefficients in concentrated solutions of strong electrolytes. ${ }^{9}$ In the present case, the following simultaneous processes take place besides the diffusion of the reacting species to the electrode surface, (a) transfer of ions of the supporting electrolyte, (b) transfer of species yielded by the electrochemical reaction itself, (c) changes of viscous forces due to the presence of a large ionic concentration and (d) transfer of solvent molecules (which might be differently associated with the reacting ions), and all should be considered.

Since we have a great excess of supporting electrolyte, a condition imposed by the very application of the measuring method used in the present case, changes of concentration of the diffusing species will not appreciably affect its mean activity coefficient, which depends on the total ionic strength of the solution. Therefore the diffusion coefficient should show only a very small dependence on the concentration of the diffusing entities, as found.

As the concentration of the supporting electrolyte is changed, the change of 
viscosity with concentration is appreciable and causes a marked decrease of the diffusion coefficient with the increase of concentration of sodium hydroxide.

Under the present circumstances the convective diffusion of ions occurs in the same way as the diffusion of neutral molecules provided that the effect of the order of the ratio of the concentration of the reacting ion to that of the supporting electrolyte is ignored. ${ }^{10}$ Therefore the ratio $D \eta / T$, as predicted by Einstein-Stokes as well as in Eyring's theories for the diffusion of non-charged particles, ${ }^{11}$ should appear as a constant.

The constants reported in the Tables are in satisfactory agreement with earlier results of Eisenberg, Tobias and Wilke. ${ }^{2}$

Curves plotted in Fig. 5 show for any fixed concentration a ratio of $1 \cdot 20 \pm 0 \cdot 12$ between the diffusion coefficients of ferro- and ferricyanide ions. This ratio is also found between the diffusion coefficients at infinite dilution for both ions, calculated independently from their conductances.

Acknowledgements-This work was in part supported with financial aid by the Consejo Nacional de Investigaciones Cientificas y Técnicas of Argentina. J. C. B. thanks the Consejo for the Fellowship granted.

The authors are indebted to the Department of Inorganic and Physical Chemistry of the University of Buenos Aires for the original drawing of the rotating disk electrode proposed by Dr. R. Parsons and to Prof. J. J. Newman of the University of California for his interesting comments.

\section{REFERENCES}

1. M. EisenberG, C. W. Tobias and C. R. WIIKE, J. Electrochem. Soc. 101, 306 (1954).

2. M. Eisengerg, C. W. ToBias and G. R. WIIKE, J. Electrochem. Soc. 103, 413 (1956).

3. V. LeVICH, Physico-chemical Hydrodynamics (English edition), p. 57. Prentice-Hall, N.J. (1962).

4. V. LEVICH, ibid, p. 325.

5. M. von Stackelberg, M. Pllaram and V. Toome, Z. Elektrochem. 57, 342 (1953).

6. J. C. BazÁn and A. J. Arvia, Electrochim. Acta 9, 17 (1964).

7. I. M. Kolthoff and J. J. Lingane, Polarography, Vol. I, Second Edition, p. 52. Interscience, New York (1952).

8. R. A. Robinson and R. H. Stokes, Electrolyte Solutions, p. 293. Butterworth, London (1955).

9. R. A. RoBInson and R. H. Stokes, ibid, p. 309. (1952).

10. V. LEVICH, loc. cit. p. 293. (1962).

11. S. Gladstone, K. J. Lamler and H. Eyring, The Theory of Rate Processes, p. 480. McGrawHill, New York (1941). 